\title{
An evaluation of the results of media and educational campaigns designed to shorten the time taken by patients with acute myocardial infarction to decide to go to hospital
}

\author{
M Berglin Blohm, M Hartford, B W Karlson, R V Luepker, J Herlitz
}

\begin{abstract}
Objective-To describe the benefits and pitfalls of educational campaigns designed to reduce the delay between the onset of acute myocardial infarction (AMI) and its treatment.

Methods-All seven educational campaigns reported between 1982 and 1994 were evaluated.

Results-The impact on delay time ranged from a reduction of patient decision time by $35 \%$ to no reduction. One study reported a sustained reduction that resulted in the delay time being halved during the three years after the campaign. The use of ambulances did not increase. Only one study reported that survival was unaffected. There was a temporary increase in the numbers of patients admitted to the emergency department with non-cardiac chest pain in the initial phase of educational campaigns.

Conclusion-The challenge of shortening the delay between the onset of infarction and the start of treatment remains. The campaigns so far have not been proved to be worthwhile and it is not certain that further campaigns will do better. New media campaigns should be run to establish whether a different type of message is more likely to change the behaviour of people in this life-threatening situation.
\end{abstract}

(Heart 1996;76:430-434)

Department of Heart and Lung Institution, Division of Cardiology, Sahlgrenska University Hospital, Göteborg, Sweden

M Berglin Blohm

$M$ Hartford

B W Karlson

J Herlitz

Division of

Epidemiology,

University of

Minnesota,

Minneapolis, USA

R V Luepker

Correspondence to:

Dr J Herlitz, Department of Heart and Lung Institution, Division of Cardiology, Sahlgrenska University Hospital, S-413

45,Göteborg, Sweden.

Accepted for publication 23 May 1996

Keywords: delay; patient education; myocardial infarction. AMI developed during the past decade, such as thrombolysis, ${ }^{1-3} \beta$ blockers, ${ }^{4-6}$ and percutanous transluminal coronary angioplasty (PTCA), ${ }^{7-9}$ provide a rationale for reducing delay.

It is clear that the interval between the onset of symptoms and the start of intervention, particularly thrombolysis, is directly related to the outcome. The earlier such intervention is started, the better is the prognosis. ${ }^{110}$
The other crucial reason for shortening the delays in suspected AMI is the fact that most deaths from ischaemic heart disease occur outside hospital, mainly as a result of ventricular fibrillation. ${ }^{11-14}$ Many lives could be saved if patients had medical treatment to prevent the onset of a life-threatening arrhythmia.

We have examined the opportunities that there are to shorten the time taken for the patient to decide to go to hospital and the consequences of educational campaigns.

\section{Methods}

PUBLISHED REPORTS

We used the terms myocardial infarction, patient education, campaign, and delay time to search Medline for articles published in English from 1965-1995. We found three media campaigns. However, we were also aware of five further educational campaigns, which were published as abstracts at the European Congress of Cardiology $1990^{28}$ and at the American Heart Association $1993^{31}$ or as original articles in the American fournal of Cardiology 1993, ${ }^{29}$ Canadian Fournal of Public Health $1984,{ }^{25}$ and Annals of Emergency Medicine $1994 .{ }^{32}$

METHODS USED TO EVALUATE THE CAMPAIGNS The following aspects of a potential influence of media campaigns were evaluated:

- Impact on delay time

- Impact on the use of ambulance

- Awareness of campaigns among patients and in the community

- Reaction to media campaigns in the community

- Impact on the number of patients admitted to the emergency department with acute chest pain, on the number of patients admitted to hospital with suspected AMI and on the number of patients admitted to hospital with confirmed AMI

- Impact on mortality and morbidity from AMI
COMPONENTS OF DELAY BETWEEN ONSET OF SYMPTOMS AND START OF TREATMENT

Delay time has prehospital ${ }^{1516}$ and hospital phases. ${ }^{1718}$ Prehospital delay time can be divided into the patient decision time and the transport time. The transport time is influenced by various local factors including the distance 
to hospital. Some of these factors are difficult to influence. The patient's decision time can be affected by cultural factors, educational factors, age, and gender ${ }^{1920}$ and in most cases it accounts for much of the prehospital delay. ${ }^{21} 22$

The in-hospital delay is also influenced by local factors such as the site at which treatment starts, ${ }^{23}$ assignment of treatment responsibility, and other factors. This overview will focus mainly on attempts to reduce patients decision time and the results of such efforts.

\section{TARGET GROUPS}

The target groups are either patients or patients and relatives with ischaemic heart disease or the whole community. Though there are few published reports on the education of patients and their relatives, experience of education of the public by mass media campaigns is growing. ${ }^{24-30}$

\section{RATIONALE}

Is it possible to change a person's behaviour in a life-threatening situation? Experiences from patients with a previous history of myocardial infarction suggest that it is not. ${ }^{15} 33$ They have a particularly long delay time. Furthermore, it may be that such efforts frighten people more than they educate them and thus do more harm than good.

\section{IMPACT OF MEDIA CAMPAIGNS ON DELAY DURING SHORT-TERM FOLLOW UP}

The earliest campaign, conducted in Nottingham, England, was an educational programme to encourage early reporting of symptoms in over 13000 men and women over 40 registered with three general medical practices. Patients were instructed to telephone a special hospital number if they developed chest pain lasting more than 10 minutes. Patients from the three campaign practices reported chest pain earlier than patients in 10 comparison practices. There was a lower percentage of definite and probable AMIs among the calls received by the special telephone line than calls received by the patients' own doctors, implying that patients did call earlier but were more likely to call their own physician rather than the special number. The study included a comparison group which was selected by convenience rather than through a randomised design.

Since the Nottingham study ${ }^{24}$ there have been at least eight media campaigns designed to educate the public about the dangers of acute chest pain and the possibility of improving outcomes if treatment is started early.
The first of these campaigns called Signals and Action was run in Halifax, Canada. It was a short term campaign with a pre-test period of four weeks, a campaign period of eight weeks, and a post-test period of one week, three months after the end of the campaign. During the pre-test period $16 \%$ of patients with acute chest pain were admitted to hospital within two hours after onset of chest pain as compared with $32 \%$ during the campaign $(P<0.05)$. In the post-test period, $29 \%$ presented within two hours. ${ }^{25}$

In the Göteborg Heart Pain 90000 campaign, a one-year media campaign was preceded by a 21-month control period. The median delay time between onset of pain and arrival in hospital among AMI patients fell from 3 hours during the control period to 2 hours 20 min during the year of the campaign $(P<$ $0.001) .{ }^{26}$

In Seattle, a two month educational campaign was evaluated by comparing a pre-test period of 4.5 months and a post-test period of the same duration. The campaign did not significantly shorten patient delay in seeking care (pre-message median delay of $2 \cdot 6$ hours; postmessage median delay of $2 \cdot 3$ hours). ${ }^{27}$

A media campaign in the city of Ludwigshafen in Germany was more successful. ${ }^{28}$ During a pre-test period of 4 months, $42 \%$ of patients with acute chest pain arrived at hospital within 2 hours of the onset of pain as compared with $82 \%$ during the campaign $(\mathrm{P}<$ $0.05)$. The median delay decreased from 4.0 hours before the campaign to $3 \cdot 2$ hours during it.

In a two year media campaign in Jacksonville, Illinois, the delay after the campaign did not differ significantly from that before it. ${ }^{29}$

The National Heart Week in Australia took place in 1989. Three surveys of coronary care units in various parts of Australia were performed, six months before the campaign, one month before it, and six months after it. The mean delay between the onset of symptoms and arrival at hospital remained similar during these three periods; 8.9 hours, 8.6 hours, and 8.3 , hours respectively. ${ }^{30}$

Under the slogan "Heart attack? Every minute counts! Call 144", a one-year media campaign was performed in Geneva in Switzerland. In chest pain patients, the median delay was reduced from 3 hours 0 minutes before the campaign to 2 hours 40 minutes during it. ${ }^{31}$ The table summarises these campaigns.

Results of various campaigns in terms of impact on delay time between onset of symptoms and arrival in hospital

\begin{tabular}{|c|c|c|c|c|c|c|}
\hline \multirow[b]{2}{*}{ Country } & \multirow[b]{2}{*}{ Year } & \multirow[b]{2}{*}{ Duration * } & \multicolumn{2}{|c|}{ Number of patients } & \multicolumn{2}{|l|}{ Delay time } \\
\hline & & & Control & Campaign & Control & Campaign \\
\hline Canada & 1983 & 2 mnth & 101 & 41 & $\leqslant 2 h(16 \%) \ddagger$ & $(29 \%) \ddagger$ \\
\hline USA & 1987 & $2 \mathrm{mnth}$ & 401 & 489 & Med d $2 \cdot 6 \mathrm{~h}$ & $2 \cdot 3 \mathrm{~h}$ \\
\hline Germany & 1989 & $6 \mathrm{mnth}$ & 203 & 302 & Med d 4h & $3 \cdot 2 \mathrm{~h}$ \\
\hline Sweden & 1988 & $1 \mathrm{yr}$ & 768 & 496 & Med d $3 h$ & $2 \mathrm{~h} 20 \mathrm{~min}$ \\
\hline Australia & 1989 & $1 \mathrm{wk}$ & 221 & 253 & Med d $1 \mathrm{~h} \dagger$ & Med d lh \\
\hline USA & 1989 & $2 \mathrm{yr}$ & 66 & 67 & Med d $1 \mathrm{~h} 43 \mathrm{~min}$ & Med d $1 \mathrm{~h} 52 \mathrm{~min}$ \\
\hline Switzerland & 1992 & $1 \mathrm{yr}$ & 1075 & 640 & Med d 3h & Med d $2 \mathrm{~h} 40 \mathrm{~min}$ \\
\hline
\end{tabular}

^Duration of campaign.

Time to seek help.
fPercentage of patients who arrived in hospital less than 2 hours after onset of pain.

Med d, median delay. 


\section{Comment}

The experiences of different media campaigns in industrialised countries provide conflicting results for impact on delay time in AMI patients. The reasons for these differences may vary. The delay time was short before the start of the campaigns in Seattle and Jacksonville, making it less likely to be reduced still further. In other campaigns there was greater potential for reduction.

LONG-TERM IMPACT ON DELAY TIME

In only one of the campaigns was the impact on long-term follow up evaluated. ${ }^{34}$ In the Göteborg campaign, the median delay remained significantly lower in the three years after the campaign ended ( 2 hours $20 \mathrm{~min}$ compared with 3 hours before it started).

\section{IMPACT ON THE AMBULANCE USE}

There is no evidence that media campaigns increase ambulance use. ${ }^{2635}$ The use of ambulances in AMI appears to have remained stable over the past two decades. ${ }^{36}$

\section{IMPACT ON INFARCT SIZE}

Only one of the campaigns evaluated the impact on estimated infarct size. Infarct size was limited by shortening the delay. ${ }^{37}$

IMPACT ON THE PROGNOSIS

The only campaign which evaluated the effect on mortality ${ }^{37}$ found no difference in mortality during the year of the campaign compared with the previous period. However, both before and during the campaign, the use of thrombolytic agents was low compared with the current era.

WHAT HAPPENS AT THE DISPATCH CENTRE? A recent campaign in Seattle, showed that the use of the 911 emergency number increased during the campaign, but rapidly diminished after its completion. ${ }^{32}$ Similarly, the number of patients calling the central switchboard because of acute chest pain increased during the campaign in Geneva. ${ }^{31}$

\section{WHAT HAPPENS IN THE EMERGENCY DEPARTMENT?}

The number of patients with acute chest pain attending the emergency department increases considerably when media campaigns which aim to reduce delays for patients are being run. ${ }^{313238}$ This increase consists mainly of patients with chest pain of non-cardiac origin, ${ }^{38}$ but also of patients with unstable angina pectoris and $\mathrm{AMI}^{31}$ and appears early in the campaign but then diminishes rapidly despite the continuation of the media campaign..$^{31} 38$ During the one-year media campaign in Göteborg, the number of patients who came to the emergency department with acute chest pain increased by $9 \%$ compared with the year before. $^{38}$

DOES THE NUMBER OF PATIENTS ADMITTED TO HOSPITAL WITH SUSPECTED OR CONFIRMED AMI INCREASE DURING MEDIA CAMPAIGNS? In the recent Seattle campaign, there was a considerable increase in the number of patients admitted to hospital with suspected AMI during the campaign. ${ }^{32}$ This increase declined soon after the campaign was completed. However, the number of patients with confirmed AMI did not appear to increase during the campaign. ${ }^{32}$ In the Göteborg campaign, the number of patients admitted to hospital with suspected AMI increased $5 \%$ during the year of the campaign and the number of patients with confirmed AMI increased moderately and non-significantly $(6 \%) .{ }^{38}$ In Geneva, the number of patients adimitted to hospital with AMI or unstable angina increased $27 \%$ during the first six months of the campaign. ${ }^{31}$

WHAT PROPORTION OF PEOPLE IN THE COMMUNITY CAN WE REACH WITH MEDIA CAMPAIGNS DEALING WITH ACUTE CHEST PAIN? The various campaigns have similar findings. It seems that about two thirds of the population will become aware of the message. ${ }^{25} 273139$ Younger people are aware of the message more frequently than the elderly. ${ }^{39}$ Men and women are equally aware. ${ }^{39}$ Patients with a history of cardiovascular disease are aware of the message to a similar degree as those without. ${ }^{39}$

HOW MUCH OF THE MESSAGE DO PEOPLE REMEMBER?

Telephone interviews during the Göteborg campaign found a fifth of those interviewed spontaneously remember the complete campaign message (that is, chest pain for more than 15 minutes, dial 90000 immediately for ambulance transport to hospital). ${ }^{39}$

COMMUNITY REACTION TO CAMPAIGNS ABOUT THE DANGER OF CHEST PAIN?

In the Göteborg media campaign, most people in the community reacted positively $(83 \%)$. In fact, only $1 \%$ regarded the campaign as something frightening. ${ }^{39}$

HOW MUCH DO THE CAMPAIGNS COST?

In Jacksonville with a total population of 55000 the cost of the two year campaign was $\$ 10000$ for the first year while the cost of the second year was totally sponsored.

In the two short-term campaigns in King County, Seattle with a population of 1 million, the cost was $\$ 140000^{26}$ and $\$ 245000^{32}$ respectively.

In the one year campaign in Göteborg with a population of 450000 , the total cost was $\$ 400000$, which includes $\$ 285000$ sponsorship, giving a net cost of $\$ 115000$.

\section{Discussion}

A weakness of this overview is the absence of details concerning the content of the programmes and the media involved. Doubtless the media chosen varied between studies and with the intensity of the programme, the details available were sometimes too limited to allow further consideration.

In some areas, media campaigns reduced 
delays in AMI. It may be that the impact on patient decision time is even larger than the reported effect on total delay time, because the latter also included transport time. Thus in the Göteborg campaign we found that the total delay between onset of pain and admission to hospital was reduced by $22 \%$ whereas patient decision time was reduced by $35 \% .{ }^{26}$ However, there are currently no reports to indicate that media campaigns improve survival. In the only study in which this issue was addressed, the use of thrombolytic agents was very low during the campaign. ${ }^{37}$ Media campaigns about acute chest pain caused a temporary increase in the number of patients coming to the emergency departments with noncardiac acute chest pain, as well as in the number of calls to emergency centres, but the number of patients admitted to hospital with AMI did not increase or increased only moderately.

ARE THERE OTHER WAYS OF REDUCING DELAYS IN AMI?

Several studies have been performed to evaluate the impact of prehospital thrombolysis in AMI on survival as compared with thrombolysis initiated in hospital. ${ }^{40-44}$ This approach further reduced delay times. Summary of the individual results from these trials in a metaanalysis found that pre-hospital thrombolysis significantly increases survival. ${ }^{43}$

Although prehospital delay is the major component of the total delay between the onset of AMI symptoms and the start of treatment, the hospital procedure time is often unnecessarily long. ${ }^{1819}$ Previous studies have reported that it is possible to shorten the hospital procedure time considerably..$^{23}{ }^{45-48}$ In many community hospitals, the introduction of emergency chest pain rooms appears to be one solution to this problem. ${ }^{49}$ Another approach is to transport the patients directly from the ambulance to the coronary care unit, bypassing the emergency department.

\section{FUTURE ASPECTS}

Shortening the delay between the onset of infarction and the start of treatment remains a challenge. The campaigns performed so far have not really proved to be worthwhile and it is not certain that further campaigns will do better. New media campaigns should be run to establish whether a different type of message is more likely to change the behaviour of people in this life-threatening situation.The aim is to increase the prehospital initiation of treatment for AMI and reduce the within hospital delay.

1 Gruppo Italiano per lo Studio della Streptochinasi nell Infarto miocardico (GISSI). Effectiveness of intravenous thrombolytic treatment in acute myocardial infarction. Lancet 1986;i:397-402.

2 ISIS-2 (Second International Study of Infarct Survival) Collaborative Group. Randomised trial of intravenous streptokinase, oral aspirin, both or neither among 17187 cases of suspected acute myocardial infarction: ISIS-2. Lancet 1988;ii:349-60.

3 White HD, Norris RM, Brown MA, Takayama $M$, tokinase on left ventricular function and early survival after acute myocardial infarction. $N$ Engl $\mathcal{f}$ Med 1987; 317:850-5.

4 Hjalmarson $\AA$, Elmfeldt D, Herlitz J, Holmberg S, Málek I, Nyberg G, et al. Effect on mortality of metoprolol in acute myocardial infarction. Lancet 1981;ii:823-7.

5 The MIAMI Trial Research Group. Metoprolol in acute myocardial infarction: A randomized placebo controlled international trial. Eur Heart f 1985;6:199-226.

6 ISIS-I Collaborative Group: A randomized trial of intravenous atenolol among 16027 cases of suspected acute myocardial infarction. Lancet 1986;ii:57-66.

7 Grines CL, Browne KF, Marco J, Rothbaum D, Stone GW, O'Keefe J, et al. For the Primary Angioplasty in Myocardial Infarction Study Group. A comparison of immediate angioplasty with thrombolytic therapy for acute myocardial infarction. $N$ Engl $\mathcal{F}$ Med 1993:328;

8 Zijlstra F, de Boer MJ, Hoorntje JCA, Reiffers S, Reiber $\mathrm{JH}$, Suryapranata $\mathrm{H}$. A comparison of immediate coronary angioplasty with intravenous streptokinase in acute myocardial infarction. N Engl f Med 1993;328:680-4.

9 Gibbons RJ, Holmes DR, Reeder GS, Balley KR, Hopfenspirger MR, Gersh BJ. For the Mayo Coronary Care Unit and Catheterization Laboratory Groups. Immediate angioplasty compared with the administration of a thrombolytic agent followed by conservative treatment for myocardial infarction. N Engl $f$ Med 1993; 328:685-91.

10 Fibrinolytic Therapy Trialists' (FTT) Collaborative Group: Indications for fibrinolytic therapy in suspected acute myocardial infarction: collaborative overview of early mortality and major morbidity results from all ranearly mortality and major morbidity results from all ran-
domised trials of more than 1000 patients. Lancet domised trials of

11 Cobb LA, Werner JA, Trobaugh GB. Sudden cardiac death: a decade's ex-perience with out-of-hospital resuscitation. Mod Concepts Cardiovasc Dis 1980;49:31-6.

12 Cobb LA, Baum RS, Alvarez III H, Schaffer WA. Resuscitation from out-of-hospital ventricular fibrillation: 4 years follow-up. Circulation 1975;51,52:(suppl III); 223-8.

13 Roth R, Stewart RD, Rogers K, Camon GM. Out-of-hospital cardiac arrest: factors associated with survival. Ann Emerg Med 1984;13:237-43.

14 Weaver WD, Cobb LA, Hallstrom AP, Copass MK, Ray R, Emery $\mathrm{M}$, et al. Considerations for improving survival from out-of-hospital cardiac arrest. Ann Emerg Med 1986;15:1181-6.

15 Moss AJ, Goldstein S. The pre-hospital phase of acute myocardial infarction. Circulation 1970;41:737-42.

16 Schmidt SB, Borsch MA. The prehospital phase of acute myocardial infarction in the era of thrombolysis. $A m \mathcal{F}$ Cardiol 1990;65:1411-5.

17 Sharkey SW, Brunette DD, Ruiz E, Hession WT, Wysham DG, Goldberg IF, et al. An analysis of time delays preceding thrombolysis for acute myocardial infarction. $\mathscr{f} A M A$ 1989;262:3171-4

18 Hartford M, Herlitz J, Karlson BW, Risenfors $M$. Components of delay time in suspected acute myocardial infarction with particular emphasis on patient delay. $\mathcal{F}$ Intern Med 1990;228:519-23.

19 Herlitz J, Blohm M, Hartford M, Hjalmarson $\AA$, Holmberg $S$, Karlson BW. Delay time in suspected acute myocardial infarction and the importance of its modification. Clin Cardiol 1989;12:370-4.

20 Hackett TP, Cassem NH. Factors contributing to delay in responding to the signs and symptoms of acute myocardial infarction. Am 7 Cardiol 1969;24:651-8.

21 Simon AB, Feinleib M, Thompson HK. Component of delay in the pre-hospital phase of acute myocardial infarction. Am $\mathcal{F}$ Cardiol 1972;30:476-82.

22 Schroeder JS, Lamb IH, Hu M. The prehospital course of patients with chest pain. Analysis of the prodromal, symptomatic, decision-making, transportation and emergency room period. Am $\mathcal{F} M e d$ 1978;64:742-8.

23 MacCallum AG, Stafford PJ, Jones C, Vincent R, PerezAvila C, Chamberlain DA. Reduction in hospital time to thrombolytic therapy by audit of policy guidelines. Eur Heart $\mathcal{F} 1990 ; 11$ (suppl F):48-52.

24 Rowley JM, Hill JD, Mitchell JRA. Early reporting of myocardial infarction: Impact of an experiment in patient education. Br Med $₹$ 1982;284:1741-6.

25 Mitic WR, Perkins J The effect of a media campaign on heart attack delay and decision times. Can $\mathcal{F}$ Publ Health 1984;75:414-8.

26 Herlitz J, Blohm M, Hartford M, Karlson BW, Luepker R, Holmberg $S$, et al. Follow-up of a 1-year media campaign on delay times and ambulance use in suspected acute myocardial infarction. Eur Heart f 1992;13:171-7.

27 Ho MT, Eisenberg MS, Litwin PE, Schaeffer SM, Damon SK. Delay between onset of chest pain and seeking medical care: The effect of public education. Ann Emerg Med 1989;18:727-31

28 Rustige JM, Burczk U, Schiele R, Werner A, Senges J. Media campaign on delay times in suspected myocardial infarction. The Ludwigshafen community project (abstract). Eur Heart f 1990;11 (suppl): 171:p862.

29 Moses HW, Engelking N. Taylor GJ, Prabhakar C, Vallala $\mathrm{M}$, Colliver JA, et al. Effect of a two-year public education campaign on reducing response time of patients with symptoms of acute myocardial infarction. Am $¥$ Cardio 1991;68:249 51 .

30 Bett N, Aroney G, Thompson P. Impact of a national educational campaign to reduce patient delay in possible heart attack. Aust NZ F Med 1993;23:157-61. 
31 Gaspoz J-M, Unger P-F, Urban P, Chevrolet JC, Rutishauser W, Lovis C, et al. Impact of a public campaign on pre-hospital delay in patients reporting chest paign on pre-hospital delay

32 Eppler E, Eisenberg MS, Schaeffer S, Meischke H, Larson MP. 9-1-1 and emergency department utilization for chest pain: results of a media campaign. Ann Emerg Med 1994;24:202-8.

33 Turi ZG, Stone PH, Muller JE, Parker C, Rude RE, Raabe $\mathrm{DE}$, et al. Implications for acute intervention related to time of hospital arrival in acute myocardial infarction. Am $\mathcal{F}$ Cardiol 1986;58:203-9.

34 Blohm M, Hartford M, Karlson BW, Karlsson T, Herlitz J. A media campaign aiming at reducing delay times and increasing the use of ambulance in AMI. Am 7 Emerg Med 1994;12:315-8.

35 Herlitz J, Hartford M, Blohm M, Karlson BW, Ekström L, Risenfors M, et al. Effect of a media campaign on delay times and ambulance use in suspected acute myocardial infarction $A m$ Cardiol $1989964: 90-3$

36 Wennerblom B, Holmberg S, Wedel $\mathrm{H}$. The effect of a mobile coronary care unit on mortality in patients with acute myocardial infarction or cardiac arrest outside hospital. Eur Heart $\mathcal{F}$ 1982;3:504-15.

37 Blohm M, Herlitz J, Hartford M, Karlson BW, Risenfors M, Luepker RV, et al. Consequences of a media campaign focusing on delay in acute myocardial infarction. Am ₹ Cardiol 1992;69:41 1-3.

38 Herlitz J, Hartford M, Karlson BW, Risenfors M, Blohm M, Luepker RV, et al. Effects of a media campaign to reduce delay times for acute myocardial infarction on the burden of chest pain patients in the emergency departburden of chest pain patients in
ment. Cardiology 1991;79:127-34.

39 Blohm M, Herlitz J, Schröder U, Hartford M, Karlson BW, Risenfors M, et al. Reaction to a media campaign focusing on delay in acute myocardial infarction. Heart Lung 1991;20:661-6.

40 Castaigne AD, Herve C, Duval-Moulin AM, Gaillard M,
Dubois-Rande JL, Boesch C, et al. Prehospital use of APSAC: results of a placebo-controlled study. $A m \stackrel{f}{ }$ Cardiol 1989;64:30A-33A

41 Schofer J, Buttner J, Geng G, Gutschmidt K, Herden HN, Mathey DG, et al. Prehospital thrombolysis in acute myocardial infarction. Am $\mathcal{f}$ Cardiol 1990;66: 1429-33.

, Cerqueria $M$, Hallstrom AP, Litwin PE, Martin JS, Kudenchuk PJ, et al. For the myocardial infarction triage and intervention project group. Pre-hospital-initiated vs hospital-initiated thrombolytic therapy. The myocardial infarction triage and intervention trial. fAMA 1993;270:1211-6.

43 The European Myocardial Infarction Project Group Prehospital thrombolytic therapy in patients with suspected acute myocardial infarction. $N$ Engl $f$ Med 1993 329:383-9.

44 Rawles J. Halving of mortality at 1 year by domiciliary thrombolysis in the Grampian Region Early Anistreplase Trial (GREAT). f Am Coll Cardiol 1994;23:1-5.

45 Burns JMA, Hogg KJ, Rae AP, Hillis WS, Dunn FG. Impact of a policy of direct admission to a coronary care unit on use of thrombolytic treatment. $\mathrm{Br}$ Heart $\mathcal{f}$ 1989;61:322-5.

46 Saetta IP, Quinton D, Dacruz D, Barnes $M$. Delay in thrombolytic treatment in acute myocardial infarction: the role of the accident and emergency department. Arch Emerg Med 1990;7:206-11.

47 Moses HW, Bartolozzi J, Koester DL, Colliver JA, Taylor GJ, Mikell FL, et al. Reducing delay in the emergency room in administration of thrombolytic therapy for room in administration of thrombolytic therapy for myocardial infarction associated with ST elevation. 0

8 Pell ACH, Miller HC, Robertson CE, Fox KAA. Effect of "fast track" admission for acute myocardial infarction on delay to thrombolysis. Br Med f 1992;304:83-7.

$49 \mathrm{Bahr}$ RD. Reducing time to therapy in AMI patients: The new paradigm. Am $\mathcal{F}$ Emerg Med 1994;12:501-3. 